\title{
Retinal ganglion cell survival and axon regeneration in WId transgenic rats after optic nerve crush and lens injury
}

\author{
Barbara Lorber ${ }^{1}$, Alessia Tassoni ${ }^{1}$, Natalie D Bull1 ${ }^{1}$, Marilita M Moschos ${ }^{1,2}$ and Keith R Martin ${ }^{1,3,4,5^{*}}$
}

\begin{abstract}
Background: We have previously shown that the slow Wallerian degeneration mutation, whilst delaying axonal degeneration after optic nerve crush, does not protect retinal ganglion cell (RGC) bodies in adult rats. To test the effects of a combination approach protecting both axons and cell bodies we performed combined optic nerve crush and lens injury, which results in both enhanced RGC survival as well as axon regeneration past the lesion site in wildtype animals.
\end{abstract}

Results: As previously reported we found that the WId $d^{S}$ mutation does not protect RGC bodies after optic nerve crush alone. Surprisingly, we found that WId $d^{S}$ transgenic rats did not exhibit the enhanced RGC survival response after combined optic nerve crush and lens injury that was observed in wildtype rats. RGC axon regeneration past the optic nerve lesion site was, however, similar in WId ${ }^{S}$ and wildtypes. Furthermore, activation of retinal glia, previously shown to be associated with enhanced RGC survival and axon regeneration after optic nerve crush and lens injury, was unaffected in WId transgenic rats.

Conclusions: RGC axon regeneration is similar between $W / d^{S}$ transgenic and wildtype rats, but $W / d^{S}$ transgenic rats do not exhibit enhanced RGC survival after combined optic nerve crush and lens injury suggesting that the neuroprotective effects of lens injury on RGC survival may be limited by the $\mathrm{WId}^{S}$ protein.

Keywords: Slow Wallerian degeneration mutation, Retinal ganglion cell, Axon regeneration, Survival, Activated retinal glia

\section{Background}

The visual system provides an excellent model for studying neuronal survival and axon regeneration after central nervous system injury. Following optic nerve lesion, axotomised adult rat retinal ganglion cells (RGC) die in large numbers. The surviving RGC only show a transient sprouting reaction with very limited axon growth past the lesion site [1]. However, it has been found that RGC survival and axon regeneration past the optic nerve lesion site can be enhanced, for example by lens injury [2-4], peripheral nerve injury [1,4], or intravitreal zymosan injection [2]. This is correlated with invasion of macrophages into the eye and activation of retinal glia, astrocytes and Müller glia [2,4,5], which produce a

\footnotetext{
*Correspondence: krgm2@cam.ac.uk

'Centre for Brain Repair, University of Cambridge, Cambridge, UK

${ }^{3}$ Cambridge NIHR Biomedical Research Centre, Cambridge, UK

Full list of author information is available at the end of the article
}

variety of growth factors, including oncomodulin [6,7] and ciliary neurotrophic factor/apolipoprotein E respectively $[5,8]$. The role of macrophages in mediating RGC survival and axon regeneration has recently been challenged [9] and activated retinal glia have been shown to be important mediators of this response $[5,8]$.

We have previously shown that the slow Wallerian degeneration mutation $\left(W l d^{S}\right)$ delays RGC axon degeneration in adult rats after optic nerve injury, but does not reduce cell body death compared to wildtype animals [10]. To test the effects of a combination approach protecting both axons and cell bodies we performed combined optic nerve crush and lens injury, which enhances RGC survival as well as axon regeneration in wildtype rats [2-4]. This is also of particular interest in terms of the effects of the Wld $d^{S}$ mutation on the axon regeneration potential in the central nervous system (CNS) because previous studies have mainly focused on peripheral

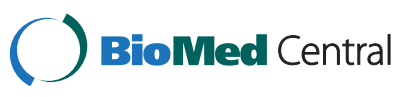


nervous system (PNS) regeneration in mice, in which the mutation first arose $[11,12]$. Whilst there have been reports that axonal regeneration is impaired in $\mathrm{Wld}^{S}$ transgenic mice, it has also been shown that they are able to regenerate normally in an appropriate environment $[11,13,14]$.

Interestingly, we found that whilst optic nerve crush and lens injury did not lead to enhanced RGC survival in $W l d^{S}$ transgenic rats, these cells were nevertheless able to successfully re-grow RGC axons past the optic nerve lesion site.

\section{Results}

We have previously confirmed that transgenic $W l d^{S}$ rat RGC express the $W l d^{S}$ protein, and that their axons show delayed Wallerian degeneration after optic nerve crush [10].

\section{RGC axon regeneration}

Two weeks after optic nerve crush alone, only a small number of adult rat RGC axons were able to grow past the optic nerve lesion site in both wildtype and $W l d^{S}$ transgenic rats with no significant difference between the two (Figure 1A-C). However, optic nerve crush combined with lens injury significantly increased the number of RGC axons crossing the optic nerve lesion site and growing into the distal optic nerve stump at 14 days post-injury. This regeneration response, whilst appearing slightly stronger in wildtype rats (wildtype: $\mathrm{P}<0.01$, $W l d^{S}: \mathrm{P}<0.05$ versus optic nerve crush), was not significantly different to that found in $W l d^{S}$ transgenic rats (Figure 1A,D,E). Therefore, RGC axon regeneration was similar between wildtype and $W l d^{S}$ transgenic rats.

\section{RGC survival}

For ease of RGC identification we used Islet-1, which is expressed by RGC as well as by displaced amacrine cells in the ganglion cell layer. Islet-1 is also expressed by some cells in the inner nuclear layer $[15,16]$. However, as it was previously shown that amacrine cells are not affected by optic nerve lesions $[17,18]$, changes in Islet- 1 labelling in the ganglion cell layer are likely to be due to changes in the number of surviving RGC, though we can not exclude that lens injury may have had an effect on amacrine survival.

We found that, as previously reported [10], two weeks after optic nerve crush, RGC survival was reduced to a third of control retinas and did not differ between wildtype and $W l d^{S}$ transgenic rats. Interestingly, whilst lens injury at the time of optic nerve crush led to a significant increase in RGC survival $(\mathrm{P}<0.01)$ in wildtype rats, it did not affect RGC survival in $W l d^{S}$ transgenic rats (Figure 2A-G). Thus, whilst RGC survival was similar in both genotypes following optic nerve crush alone, optic nerve crush combined with lens injury revealed that, in contrast to wildtypes, no enhanced RGC survival response occurred in $W l d^{S}$ transgenic rats.

\section{Retinal glia activation}

In both untreated wildtype and $W l d^{S}$ transgenic rats expression of glial fibrillary acidic protein (GFAP) was restricted to astrocytic processes in the nerve fibre layer of the retina (Figure 3B,C). In both genotypes, fourteen days after optic nerve crush alone occasional Müller glia had become activated as evidenced by increased GFAP expression, with cell processes crossing the retinal layers (Figure $3 \mathrm{~A}, \mathrm{D}, \mathrm{E})$. Combination of optic nerve crush with lens injury led to a significant increase in retinal glia activation over that observed in optic nerve crush alone, in both wildtype $(\mathrm{P}<0.001)$ and $\mathrm{Wld}^{S}$ transgenic rats $(\mathrm{P}<0.001)$ with pronounced GFAP expression visible in Müller glia throughout the retina (Figure 3A,F,G). Retinal glia activation after optic nerve crush was not significantly different between $W l d^{S}$ transgenic and wildtype rats. Thus, activation of retinal glia occurred to a similar extent in wildtype and $W l d^{S}$ transgenic rats.

\section{Discussion}

The $W l d^{S}$ mutation has long been linked with delayed Wallerian degeneration in the PNS and CNS after injury [10-12] but relatively few studies have looked at the axon regenerative potential in $W l d^{S}$ transgenic animals. Almost all of these studies have focused on $\mathrm{Wld}^{S}$ transgenic mice and investigated the regeneration potential after peripheral nerve injury $[11,13,14]$, with only one study looking at recovery after injury to the CNS. Whilst this study found that locomotor recovery after partial spinal cord injury was delayed in $W l d^{S}$ transgenic mice, it was suggested that the speed with which recovery occurred in wildtype mice was likely to result from changes in functional plasticity rather than axon regeneration [19].

The present study is therefore the first to look at axon regeneration of $W l d^{S}$ transgenic rats, a recently generated strain [20], after injury to the CNS using a unique model, the optic nerve crush model, in which it is possible to stimulate successful RGC axon regeneration in wildtype rats when optic nerve crush is combined with lens injury [2-4]. Interestingly, we found that whilst the regeneration response was slightly stronger in wildtype rats, $W l d^{S}$ transgenic rats were able to successfully grow RGC axons past the optic nerve lesion site after optic nerve crush and lens injury, with regeneration not being significantly different from wildtypes. We also found that activation of retinal glia, previously shown to mediate RGC survival and axon regeneration response after optic nerve crush and lens injury in wildtype rats [5,8], occurred to a similar extent between $W l d^{S}$ transgenic and 

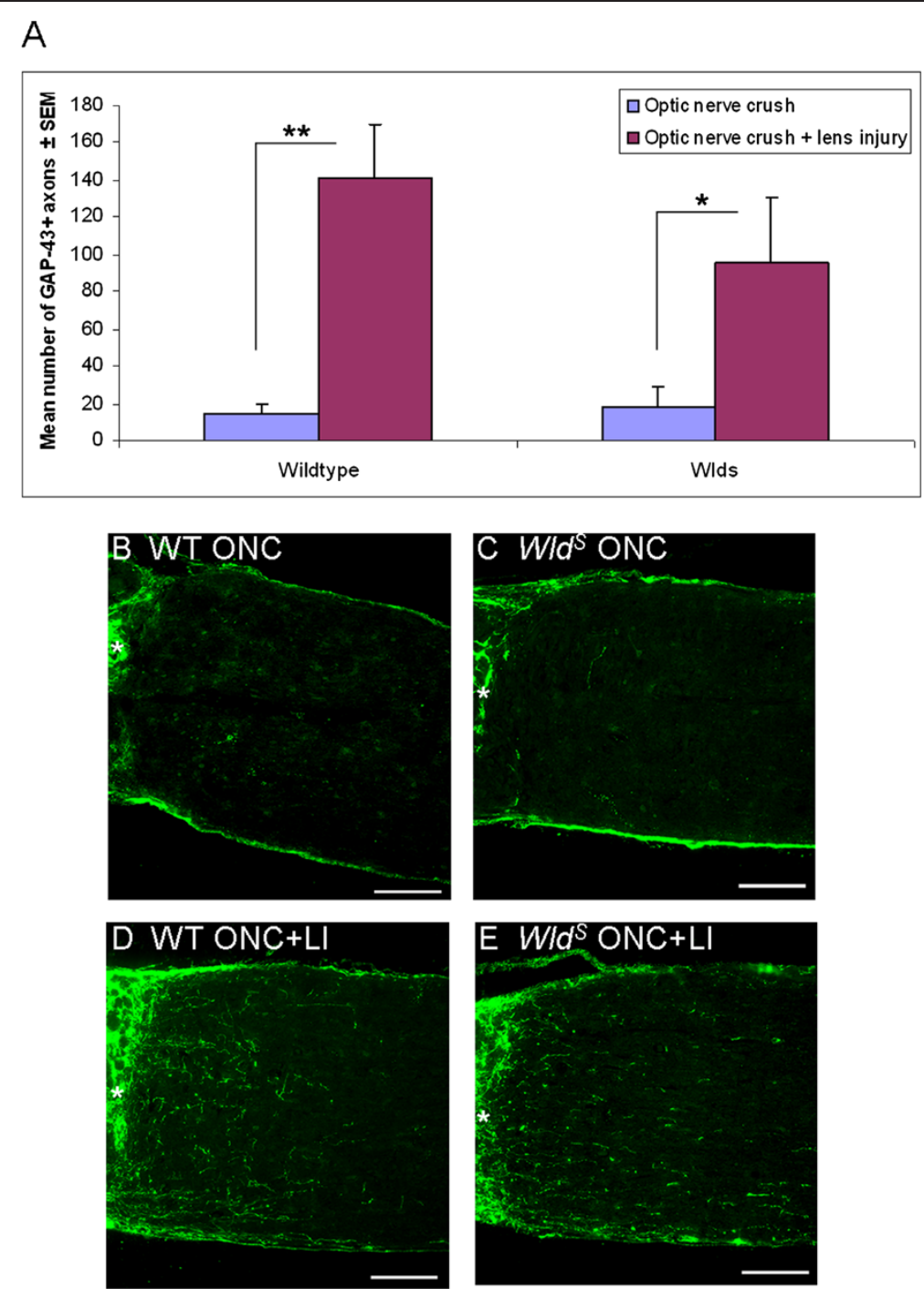

Figure 1 RGC axon regeneration is similar between $W I d^{5}$ transgenic and wildtype rats after optic nerve crush and lens injury

(A) Quantification of the mean number of RGC axons extending $250 \mu \mathrm{m}$ past the optic nerve lesion site 14 days after either optic nerve crush alone, or in combination with lens injury in adult wildtype or $W\left(d^{S}\right.$ transgenic rats. Significant differences are indicated by asterisk $(P<0.05=*$; $\mathrm{P}<0.01=^{* *}$ ). Images of RGC axon regeneration past the optic nerve lesion site (indicated by asterisk), 14 days after ( $\left.\mathbf{B}, \mathbf{C}\right)$ optic nerve crush alone or $(\mathbf{D}, \mathbf{E})$ in combination with lens injury in wildtype and $W / d^{S}$ transgenic rats. $\mathrm{WT}=$ Wildtype; ONC=Optic nerve crush; ONC $+\mathrm{LI}=\mathrm{Optic}$ nerve crush + lens injury; Scale bars: $100 \mu \mathrm{m}$.

wildtype rats. This finding shows that successful CNS axon regeneration can indeed occur in $W l d^{S}$ transgenic rats.

Delayed Wallerian degeneration in the CNS compared to the PNS has long been associated with axon regenerative failure after CNS injury [21]. We have recently shown that in $W l d^{S}$ transgenic rats Wallerian degeneration after optic nerve injury is also delayed [10]. Successful RGC axon regeneration through the normally inhibitory environment of the distal optic nerve in wildtype rats after lens injury has been associated with an altered growth-disinhibitory phenotype, potentially through release of metalloproteinases from regenerating
RGC axons, which degrade myelin-derived inhibitory ligands in the distal optic nerve stump [22]. This may also explain why successful RGC axon regeneration induced by lens injury can occur in $W l d^{S}$ transgenic rats where Wallerian degeneration is even further delayed.

Our findings are in line with a study in $W l d^{S}$ transgenic mice where the $W l d^{S}$ mutation did not appear to alter the growth phenotype compared to wildtype mice, as sensory dorsal root ganglion axons regenerated normally, although only in an optimal environment where Wallerian degeneration was experimentally enhanced [14].

Whilst RGC axon regeneration past the optic nerve lesion site was similar between $W l d^{S}$ transgenic rats and 

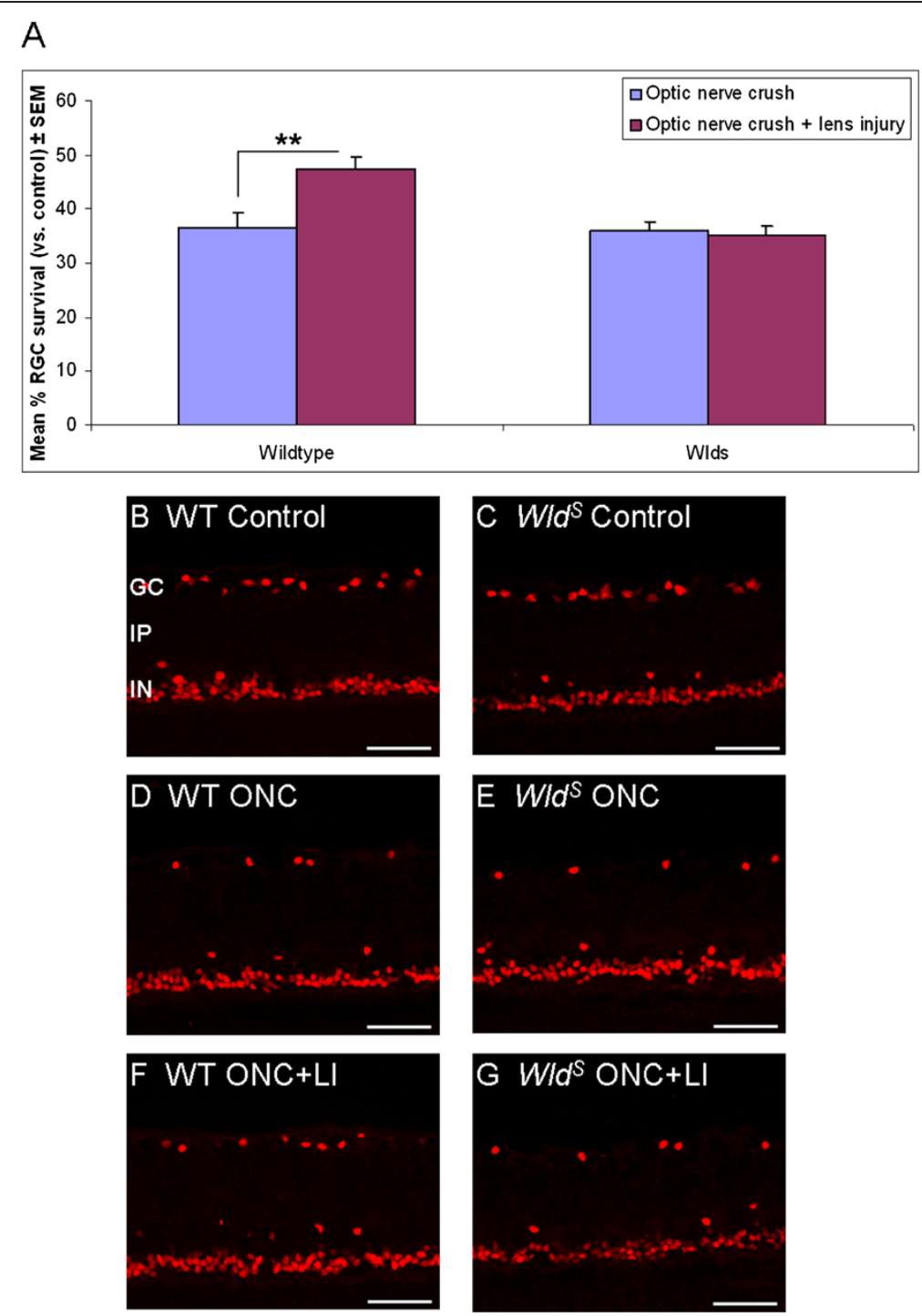

Figure 2 Enhanced RGC survival does not occur in WId ${ }^{S}$ transgenic rats after optic nerve crush and lens injury. (A) Percentage of surviving RGC (compared to control) 14 days after either optic nerve crush alone or in combination with lens injury in adult wildtype and WI $d^{5}$ transgenic rats. Significant differences are indicated by asterisk $\left(P<0.01=^{* *}\right)$. Cross-sections through adult wildtype or WId retinae stained for Islet-1 (to identify RGC in the ganglion cell layer) from (B, C) control (untreated), or 14 days after (D, E) optic nerve crush, or (F, G) optic nerve crush in combination with lens injury. $\mathrm{GC}=$ Ganglion cell layer; $I \mathrm{P}=$ Inner plexiform layer; $\mathbf{I N}=$ Inner nuclear layer; $W T=$ Wildtype; ONC = Optic nerve crush; ONC + LI = Optic nerve crush + lens injury; Scale bars: $50 \mu \mathrm{m}$.

wildtypes, we found that the significantly enhanced RGC survival that occurred in wildtype rats after optic nerve crush and lens injury did not occur in $W l d^{S}$ transgenic rats. These results could be consistent with $W l d^{S}$ transgenic rats indeed having an enhanced RGC axon regeneration potential compared to wildtype rats, but this will need to be investigated more fully in future studies. It may seem surprising that, despite an absence of enhanced RGC survival in $W l d^{S}$ transgenic rats after optic nerve crush and lens injury, successful RGC axon regeneration past the lesion site occurred. However, this finding is consistent with other studies which show that survival and regeneration are not linked per se, and that these two responses to injury appear to be regulated independently and can be modulated by distinct intracellular pathways $[23,24]$.

As previously reported [10], RGC survival two weeks after optic nerve crush alone was similarly reduced to a third of control eyes in both wildtype and $W l d^{S}$ transgenic rats, suggesting that there is no somatic RGC protection conferred through $W l d^{S}$ in this model. This is in line with another study [25] which showed that there was no direct protective effect on cell bodies after induction of cell death in L4 motoneurons in $\mathrm{Wld}^{S}$ transgenic 

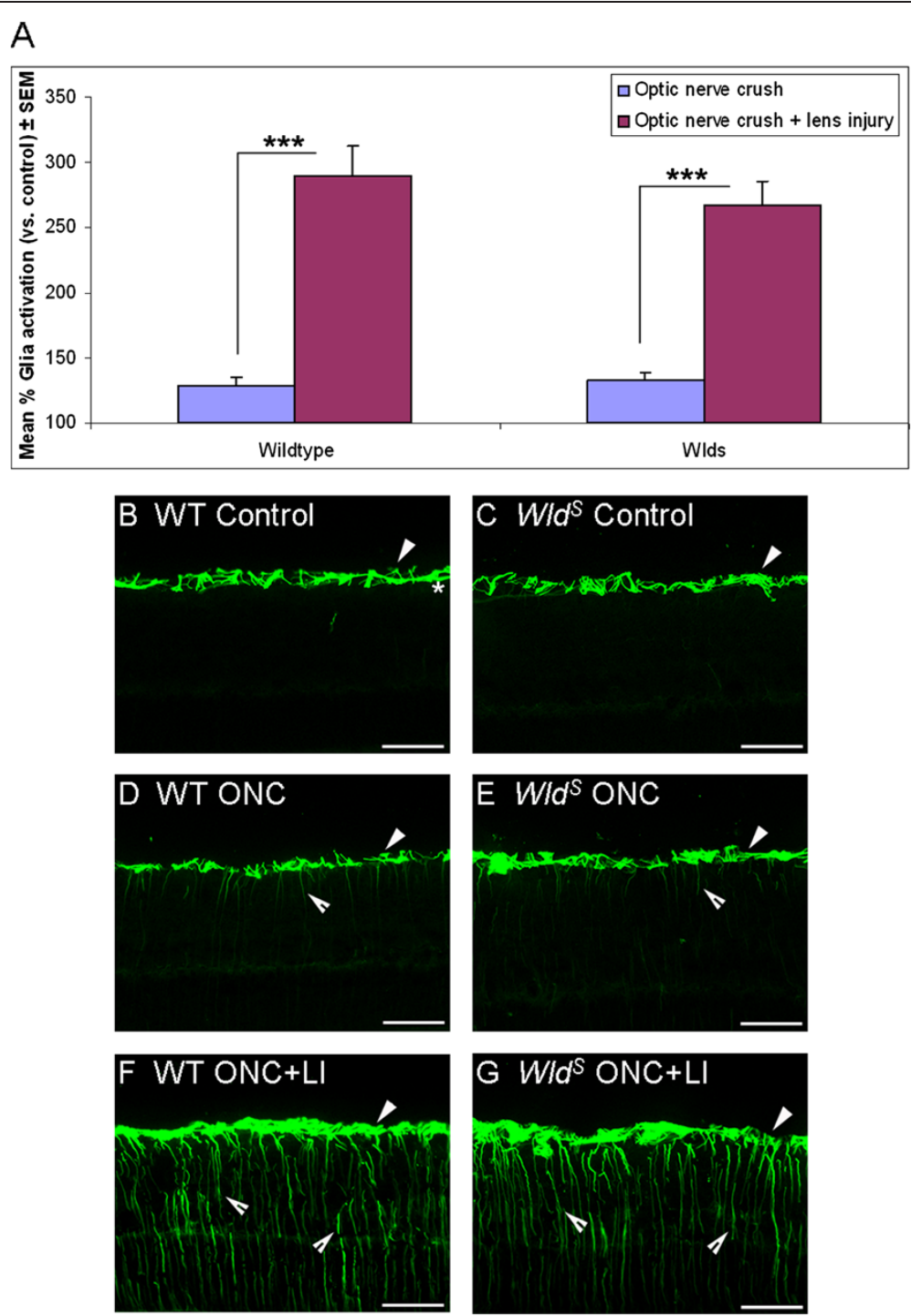

Figure 3 Retinal glia activation is similar between $W I d^{s}$ transgenic and wildtype rats after optic nerve crush and lens injury

(A) Retinal glia activation (measured as percentage increase in GFAP intensity compared to control; control set as 100\% baseline) 14 days after either optic nerve crush alone or in combination with lens injury in adult wildtype and WId transgenic rats. Significant differences are indicated by asterisk $\left(P<0.001=^{* * *}\right)$. Cross-sections through adult wildtype or WId retinae stained for presence of GFAP + astrocytes (arrowheads)/Müller glia (open arrowheads) from (B, C) control (untreated), or 14 days after $(\mathbf{D}, \mathbf{E})$ optic nerve crush, or $(\mathbf{F}, \mathbf{G})$ optic nerve crush in combination with lens injury. The RGC layer is marked in panel B by an asterisk. WT=Wildtype; ONC=Optic nerve crush; ONC $+\mathrm{LI}=$ Optic nerve crush + lens injury; Scale bars: $50 \mu \mathrm{m}$.

rats, suggesting that the observed neuroprotective effect in other injury models $[12,26]$ was most likely due to secondary axonal protection. Whilst we did not observe a neuroprotective effect of the $W l d^{S}$ protein on RGC survival in this and a previous study [10] after optic nerve crush, it is possible that secondary axonal protection may have made RGC from $W l d^{S}$ transgenic rats less responsive to survival factors released in response to lens injury.

Several mechanisms have been suggested to mediate neuroprotection in $W l d^{S}$ transgenic animals and it will be interesting to investigate in future if they interfere with RGC survival pathways activated through lens injury, thereby rendering the latter inactive in $W l d^{S}$ transgenic rats. $W l d^{S}$ is a fusion protein that consists of nicotinamide mononucleotide adenylyl-transferase-1 (Nmnat1) and a short fragment of the ubiquitin assembly protein UFD2. Whilst several reports have suggested that Nmnat is the key mediator of the neuroprotective $W l d^{S}$ effects through upregulation of nicotinamide adenine dinucleotide levels, there are some reports that have challenged this view reviewed in $[27,28]$. Other proposed 
mechanisms through which $W l d^{S}$ may confer neuroprotection include changes in gene expression, such as downregulation of the pituitary tumor transforming gene [29], or changes in the regulation of the cell cycle status which may "prime" neurons against future neurodegenerative insults by modifying endogenous stress pathways [30]. The latter findings were observed in uninjured $W l d^{S}$ mouse cerebella so it will be interesting to examine to what extent changes in cell cycle status occur in $W l d^{S}$ transgenic RGC and to study the effects that optic nerve crush and lens injury has on them.

There is, therefore, an array of mechanisms that have been suggested to underlie $W l d^{S}$ mediated neuroprotection, with most studies however conducted in $W l d^{S}$ transgenic mice [27]. It will be important to explore in future studies whether the same mechanisms are present in $W l d^{S}$ transgenic rats. In that respect it will also be important to investigate further the role that non-neuronal retinal cells play, in particular glial cells which are mediators of the neuroprotective responses after lens injury $[5,8]$. The majority of proteins implicated in mediating mechanisms underlying neuroprotection in $W l d^{S}$ transgenic animals are located in transgenic $W l d^{S}$ neurons and their axons, with only some weak expression observed in glia $[29,31]$. In contrast to $W l d^{S}$ transgenic mice, we previously found that retinal $W l d^{S}$ expression also localizes to cells of the inner nuclear rat retina [10], an area where Müller glia cell bodies are also located. It will therefore be important to determine whether the expression of $W l d^{S}$ and its downstream effector proteins indeed correlate to Müller glia, and whether optic nerve crush combined with lens injury modulates their expression. Such future investigations will further our understanding of the mechanisms that underlie the RGC survival and axon regeneration responses in the $W l d^{S}$ transgenic rat model.

\section{Conclusions}

In summary we have shown that whilst RGC axon regeneration is similar between $W l d^{S}$ transgenic and wildtype rats, somatic RGC protection is not conferred through, and may indeed be limited, by the $W l d^{S}$ protein following optic nerve crush and lens injury. It will be important to investigate in future studies the mechanisms that underlie these effects, and to identify combination treatments that both protect cell bodies and enhance RGC axon regeneration in $W l d^{S}$ transgenic rats.

\section{Methods}

\section{Surgical procedures}

Animals

All animal experiments were conducted in accordance with the U.K. Home Office regulations for the care and use of laboratory animals, the U.K. Animals (Scientific
Procedures) Act (1986) and the ARVO Statement for the Use of Animals in Ophthalmic and Vision Research.

Homozygous young adult, 2-3 month old, male $W l d^{S}$ transgenic rats $(\mathrm{n}=31)$ from line 79 , in which the $W l d^{S}$ cDNA transgene is driven by a $\beta$-actin promoter $[20,25]$, or age-matched Sprague Dawley rats $(n=27$; Charles River, Margate, UK) which are the background strain the $W l d^{S}$ rats arose from [20], were used for this study. Animals were kept in a pathogen controlled environment on a 12 hour light-dark cycle in standard cages and allowed to feed and drink ad libitum.

For in vivo experiments rats were assigned to three groups: optic nerve crush $(\mathrm{n}=8$; Sprague Dawley; $\mathrm{n}=9$; $\left.W l d^{S}\right)$, optic nerve crush + lens injury $(\mathrm{n}=11$; Sprague Dawley; $\mathrm{n}=13$; $W l d^{S}$ ), untreated (control; $\mathrm{n}=8$ Sprague Dawley; $\mathrm{n}=9 ; W_{l} d^{S}$.

\section{Optic nerve crush and lens injury}

Rats were anesthetized by intraperitoneal injection of ketamine $(75 \mathrm{mg} / \mathrm{kg}$ ) and domitor (medetomidine hydrochloride; $0.5 \mathrm{mg} / \mathrm{kg}$ ). Analgesics (Buprenorphine $0.03 \mathrm{mg} / \mathrm{kg}$ ) were administered pre- and post-surgery. Unilateral optic nerve crush was performed as previously described [1], avoiding injury to the retinal artery in the dural sheath (confirmed by indirect ophthalmoscopy) by incising the dorsum of the latter longitudinally before crushing the optic nerve. The lens was injured at the time of the optic nerve crush by inserting the tip of a 25 gauge needle into the eye $2 \mathrm{~mm}$ anterior to the nerve head, perpendicular to the sclera to puncture the lens to a depth of about $2 \mathrm{~mm}$. Lens injury was confirmed by direct visualization through the cornea.

\section{Immunohistochemistry on tissue sections}

Animals were transcardially perfused 14 days post-injury under terminal anaesthesia with $0.1 \mathrm{M}$ phosphate buffered saline (PBS) followed by $4 \%$ paraformaldehyde. Eyes and optic nerves were removed and post-fixed by immersion overnight in cold 4\% paraformaldehyde. Tissue was then washed with PBS and transferred to $30 \%$ sucrose solution (overnight at $4{ }^{\circ} \mathrm{C}$ ) for cryoprotection and embedded in OCT mounting medium (Raymond A. Lamb, Eastbourne, UK). Serial sections, $14 \mu \mathrm{m}$ thick, were cut with a cryostat, thaw-mounted onto glass slides (Superfrost plus, VWR, Lutterworth, UK) and stored at $-20{ }^{\circ} \mathrm{C}$ until further use.

Rehydrated eye sections were incubated in blocking solution (4\% goat serum; $0.3 \%$ Triton (Sigma) in PBS) for $60 \mathrm{~min}$ at room temperature. Primary antibodies were applied overnight at $4{ }^{\circ} \mathrm{C}$ in blocking solution: mouse antiIslet-1 homeobox (39.4D5 concentrate; 1:2000; hybridoma developed by T. Jessell and S. Brenner-Morton, concentrate from the Developmental Studies Hybridoma Bank, The University of Iowa, Iowa City, IA) and rabbit anti-GFAP 
(1:8000, DAKO, Ely, UK). Islet-1 is expressed by RGC, as well as by displaced amacrine cells in the ganglion cell layer $[15,16]$. GFAP is a marker for activated astrocytes/Müller glia [32]. The following day, slides were washed $3 \times 10 \mathrm{~min}$ in PBS and secondary antibodies (Alexa Fluor 488 goat anti-rabbit IgG; 1/1000 and Alexa Fluor 555 goat antimouse IgG; 1/1000, Invitrogen, Paisley, UK) were applied for $2 \mathrm{hrs}$ at room temperature in blocking solution. Following $3 \times 10 \mathrm{~min}$ washes in PBS, slides were mounted in Fluorsave (Calbiochem/Merck Chemicals, Beeston, UK).

Immunohistochemistry was carried out to visualize growth-associated membrane phosphoprotein-43 (GAP-43) positive axons in optic nerve sections as previously described [2]. GAP-43 is normally not detected in the mature optic nerve, but it is strongly upregulated in regenerating RGC to fill the somata and axons $[1,2,33]$. As primary antibody the IgG fraction from an anti-GAP-43 antiserum prepared in sheep (1:2500; [34]) followed by an Alexa Fluor 488 secondary antibody against sheep IgG (1:1000, Invitrogen) were used.

\section{Quantification of RGC survival/axon regeneration and retinal glia activation}

Quantification of GAP-43 positive RGC axon growth in the distal optic nerve stump was based on a previously described method [1]. Briefly, axon growth was quantified by counting the number of GAP-43 positive axons extending $250 \mu \mathrm{m}$ from the crush site into the distal optic nerve in four longitudinal sections per optic nerve, using a standard epifluorescence microscope (model DM6000B; Leica, Wetzlar, Germany). The cross-sectional width of the nerve was measured at the point at which the counts were taken and was used to calculate the number of axons per millimetre of nerve width. The number of axons was then averaged over the four sections. $\sum \mathrm{a}_{\mathrm{d}}$, the total number of axons extending distance $d$ in a nerve having a radius of $r$, was estimated by summing over all sections having a thickness $t(14 \mu \mathrm{m}): \sum \mathrm{a}_{\mathrm{d}}=\pi \mathrm{r}^{2} \mathrm{x}$ [average axons $/ \mathrm{mm}$ ] $/ \mathrm{t}$.

To evaluate RGC survival, the number of Islet-1+ cells were counted in 4 sections throughout the eye and normalised to $100 \mu \mathrm{m}$ retinal section length. Results are expressed as percentage difference versus control (control set as $100 \%$ baseline). For measuring activation of retinal glia, images of GFAP staining were taken along the retina in 4 sections throughout the eye, and the pixel intensity quantified using the Leica Application Suite (LAS AF.1.8.0) program. Results are expressed as percentage difference in GFAP activation versus control (control set as $100 \%$ baseline).

Results are expressed as mean \pm SEM of 8-13 rats per condition for each of the experimental groups. The significance of intergroup differences was evaluated by an unpaired twotailed $t$ test (assuming equal variances) and considered significant at $\mathrm{P}<0.05(\mathrm{P}<0.05=* ; \mathrm{P}<0.01=* * ; \mathrm{P}<0.001=* * *)$.

\section{Abbreviations}

CNS: Central nervous system; GAP-43: Growth-associated membrane phosphoprotein-43; GFAP: Glial fibrillary acidic protein; Nmnat1: Nicotinamide mononucleotide adenylyl-transferase-1; PBS: Phosphate buffered saline; PNS: Peripheral nervous system; RGC: Retinal ganglion cell; SEM: Standard error of the mean; $W / d^{S}$ : Slow Wallerian degeneration mutation.

\section{Competing interests}

The authors declare that they have no competing interests.

\section{Funding and acknowledgments}

This work was supported by the Jukes Glaucoma Research Fund [K.R.M] and a van Geest Fight for Sight Early Career Investigator Award [B.L].

\section{Author details}

${ }^{1}$ Centre for Brain Repair, University of Cambridge, Cambridge, UK. ${ }^{2}$ First Department of Ophthalmology, Evgenidion Hospital, University of Athens, Athens, Greece. ${ }^{3}$ Cambridge NIHR Biomedical Research Centre, Cambridge, UK. ${ }^{4}$ Eye Department, Addenbrooke's Hospital, Cambridge, UK. ${ }^{5}$ Cambridge Centre for Brain Repair, University of Cambridge, Cambridge, CB2 OPY, United Kingdom.

\section{Author's Contributions}

BL designed the study and drafted the manuscript. She also carried out surgical procedures, tissue processing and parts of the immunohistochemistry and data collection, and performed data analysis. AT did the majority of immunohistochemistry and data collection. NDB bred the $W I d^{S}$ transgenic rats. MM performed some data collection. KRM conceived of the study, participated in its design and helped to draft the manuscript. All authors read and approved the final manuscript

Received: 2 December 2011 Accepted: 6 June 2012

Published: 6 June 2012

\section{References}

1. Berry M, Carlile J, Hunter A: Peripheral nerve explants grafted into the vitreous body of the eye promote the regeneration of retinal ganglion cell axons severed in the optic nerve. J Neurocytol 1996, 25:147-170.

2. Leon S, Yin Y, Nguyen J, Irwin N, Benowitz LI: Lens injury stimulates axon regeneration in the mature rat optic nerve. J Neurosci 2000, 20:4615-4626.

3. Fischer D, Pavlidis M, Thanos S: Cateractogenic lens injury prevents traumatic ganglion cell death and promotes axonal regeneration both in vivo and in culture. Invest Ophthalmol \& Vis Sci 2000, 41:3943-3954.

4. Lorber B, Berry M, Logan A: Different factors promote axonal regeneration of adult rat retinal ganglion cells after lens injury and intravitreal peripheral nerve grafting. J Neurosci Res 2008, 86:894-903.

5. Lorber B, Berry M, Douglas MR, Nakazawa T, Logan A: Activated retinal glia promote neurite outgrowth of retinal ganglion cells via apolipoprotein E. J Neurosci Res 2009, 87:2645-2652.

6. Yin Y, Henzl MT, Lorber B, Nakazawa T, Thomas TT, Jiang F, Langer R, Benowitz LI: Oncomodulin is a macrophage-derived signal for axon regeneration in retinal ganglion cells. Nature Neurosci 2006, 9:843-852.

7. Yin Y, Cui Q, Gilbert HY, Yang Y, Yang Z, Berlinicke C, Li Z, Zaverucha-doValle C, He H, Petkova V, Zack DJ, Benowitz LI: Oncomodulin links inflammation to optic nerve regeneration. Proc Natl Acad Sci USA 2009, 106:19587-19592.

8. Müller A, Hauk TG, Fischer D: Astrocyte-derived CNTF switches mature RGCs to a regenerative state following inflammatory stimulation. Brain 2007, 130:3308-3320.

9. Hauk TG, Müller A, Lee J, Schwendener R, Fischer D: Neuroprotective and axon growth promoting effects of intraocular inflammation do not depend on oncomodulin or the presence of large numbers of activated macrophages. Exp Neurol 2008, 209:469-482.

10. Beirowski B, Babetto E, Coleman MP, Martin KR: The WldS gene delays axonal but not somatic degeneration in a rat glaucoma model. Eur J Neurosci 2008, 28:1166-1179.

11. Lunn ER, Perry VH, Brown MC, Rosen H, Gordon S: Absence of Wallerian degeneration does not hinder regeneration in the peripheral nerve. Eur J Neurosci 1989, 1:27-33. 
12. Perry $\mathrm{VH}$, Brown MC, Lunn ER: Very slow retrograde and Wallerian Degeneration in the CNS of C57BL/Ola Mice. Eur J Neurosci 1991, 3:102-105.

13. Benavides $E$, Alvarez J: Peripheral axons of Wlds mice, which regenerate after a delay of several weeks, do so readily when transcription is inhibited in the distal stump. Neurosci Lett 1998, 258:77-80.

14. Brown MC, Perry VH, Hunt SP, Lapper SR: Further studies on motor and sensory nerve regeneration in mice with delayed Wallerian degeneration. Eur J Neurosci 1994, 6:420-428.

15. Bull ND, Johnson TV, Welsapar G, DeKorver NW, Tomarev SI, Martin KR: Use of an adult rat retinal explant model for screening of potential retinal ganglion cell neuroprotective therapies. Invest Ophthalmol Vis Sci 2011, 52:3309-3320.

16. Elshatory Y, Deng M, Xie X, Gan L: Expression of the LIM-homeodomain protein Isl1 in the developing and mature mouse retina. J Comp Neurol 2007, 503:182-197.

17. Osborne NN, Perry VH: Effect of neonatal ON transection on some classes of amacrine cells in the rat retina. Brain Res 1985, 343:230-235.

18. Kielczewski JL, Pease ME, Quigley HA: The effect of experimental glaucoma and $\mathrm{ON}$ transection on amacrine cells in the rat retina. Invest Ophthalmol Vis Sci 2005, 46:3188-3196.

19. Zhang Z, Guth L, Steward O: Mechanisms of motor recovery after subtotal spinal cord injury: Insights from the study of mice carrying a mutation $\left(\mathrm{Wld}^{\mathrm{s}}\right)$ that delays cellular responses to injury. Exp Neurol 1998, 149:221-229.

20. Adalbert R, Gillingwater TH, Haley JE, Bridge $K$, Beirowski B, Berek L, Wagner D, Grumme D, Thomson D, Celik A, Addicks K, Ribchester RR, Coleman MP: $A$ rat model of slow Wallerian degeneration (WldS) with improved preservation of neuromuscular synapses. Eur J Neurosci 2005, 21:271-277.

21. Zurn AD, Bandtlow CE: Regeneration failure in the CNS: Cellular and Molecular Mechanisms. Adv Exp Med Biol 2006, 557:54-76.

22. Berry M, Ahmed Z, Lorber B, Douglas M, Logan A: Regeneration of axons in the visual system. Restor Neurol Neurosci 2008, 26:147-174.

23. Harvey AR, Hu Y, Leaver SG, Mellough CB, Park K, Verhaagen J, Plant GW, Cui Q: Gene therapy and transplantation in CNS repair: the visual system. Prog Retin Eye Res 2006, 25:449-489.

24. Pernet $V$, Di Polo A: Synergistic action of brain-derived neurotrophic factor and lens injury promotes retinal ganglion cell survival, but leads to optic nerve dystrophy in vivo. Brain 2006, 129:1014-1026.

25. Adalbert R, Nogradi A, Szabo A, Coleman MP: The slow Wallerian degeneration gene in vivo protects motor axons but not their cell bodies after avulsion and neonatal axotomy. Eur J Neurosci 2006 24:2163-2168

26. Gillingwater $\mathrm{TH}$, Haley JE, Ribchester RR, Horsburgh K: Neuroprotection after transient global cerebral ischemia in WId(s) mutant mice. J Cereb Blood Flow Metab 2004, 24:62-66.

27. Feng $Y$, Yan T, He Z, Zhai Q: Wld(S), Nmnats and axon degenerationprogress in the past two decades. Protein Cell 2010, 1:237-245.

28. Antenor-Dorsey JA, O'Malley KL: WIdS but not Nmnat1 protects dopaminergic neurites from MPP + neurotoxicity. Mol Neurodegener 2012, 7:5.

29. Gillingwater TH, Wishart TM, Chen PE, Haley JE, Robertson K, MacDonald SH, Middleton S, Wawrowski K, Shipston MJ, Melmed S, Wyllie DJ, Skehel PA Coleman MP, Ribchester RR: The neuroprotective WIdS gene regulates expression of PTTG1 and erythroid differentiation regulator 1-like gene in mice and human cells. Hum Mol Genet 2006, 15:625-635.

30. Wishart TM, Pemberton HN, James SR, McCabe CJ, Gillingwater TH: Modified cell cycle status in a mouse model of altered neuronal vulnerability (slow Wallerian degeneration; Wlds). Genome Biol 2008, 9:R101.

31. Fang C, Bernardes-Silva M, Coleman MP, Perry VH: The cellular distribution of the Wlds chimeric protein and its constituent proteins in the CNS. Neurosci 2005, 135:1107-1118.

32. Bignami A, Dahl D: The astroglial response to stabbing, Immunofluorescence studies with antibodies to astrocyte-specific protein (GFA) in mammalian and submammalian vertebrates. Neuropathol Appl Neurobiol 1976, 2:99-110.

33. Schaden H, Stürmer CA, Bähr M: GAP-43 immunoreactivity and axon regeneration in retinal ganglion cells of the rat. J Neurobiol 1994, 25:1570-1578.
34. Benowitz LI, Apostolides PJ, Perrone-Bizzozero N, Finklestein SP, Zwiers $\mathrm{H}$ : Anatomical distribution of the growth-associated protein GAP-43/B-50 in the adult rat brain. J Neurosci 1988, 8:339-352.

doi:10.1186/1471-2202-13-56

Cite this article as: Lorber et al: Retinal ganglion cell survival and axon regeneration in $W I d^{S}$ transgenic rats after optic nerve crush and lens injury. BMC Neuroscience 2012 13:56.

\section{Submit your next manuscript to BioMed Central and take full advantage of:}

- Convenient online submission

- Thorough peer review

- No space constraints or color figure charges

- Immediate publication on acceptance

- Inclusion in PubMed, CAS, Scopus and Google Scholar

- Research which is freely available for redistribution 